\title{
REVISITANDO DILTHEY: DIÁLOGOS TEÓRICOS E METODOLÓGICOS COM A FENOMENOLOGIA E A PSICOLOGIA
}

\author{
Revisiting Dilthey: theoretical and methodological dialogues with phenomenology and psychology
}

Revisando Dilthey: diálogos teóricos y metodológicos con la fenomenología y la psicología

Camila Muhl

\begin{abstract}
Resumo: Wilhelm Dilthey foi um autor fundamental para que as ciências humanas tivessem sua autonomia de método e objeto em relação às ciências naturais, entretanto, o seu trabalho ainda é pouco conhecido pelos psicólogos no Brasil. Esse artigo tem como objetivo divulgar e discutir a obra diltheyana tendo como recorte as reverberações de suas proposições para a fenomenologia e a psicologia, enquanto ciências de rigor. A análise teórica, que não pretende ser uma revisão exaustiva da obra do autor, será centrada nos temas: mundo histórico, vivência e método compreensivo de pesquisa. Para finalizar, será realizado um exercício imaginativo de como seria a psicologia atualmente se a posição de Dilthey tivesse se tornado hegemônica no campo.
\end{abstract}

Palavras-chave: Dilthey; Ciências do Espírito; Psicologia; Fenomenologia; Método.

\begin{abstract}
Wilhelm Dilthey was a fundamental author so that the human sciences had their autonomy of method and object in relation to the natural sciences, however, their work is still little known by psychologists in Brazil, so, this article aims to disclose and discuss the work of the author, having as a cut the reverberations of his propositions for phenomenology and psychology.. The theoretical analysis, which is not intended to be an exhaustive review of the author's work, will be centered on themes: historical world, experience and a comprehensive method of research. To conclude, an imaginative exercise of what psychology would be doing today if Dilthey's position had become hegemonic in the field. Keywords: Dilthey; Sciences of the Spirit; Psychology; Phenomenology; Method.
\end{abstract}

Resumen: Wilhelm Dilthey fue un autor fundamental para que las ciencias humanas tuvieran su autonomía de método y objeto en relación a las ciencias naturales, sin embargo, su trabajo todavía es poco conocido por los psicólogos en Brasil, destarte, este artículo tiene como objetivo divulgar y discutir la obra del autor, teniendo como recorte las reverberaciones de sus proposiciones para la fenomenología y la psicología, como ciencias de rigor. El análisis teórico, que no pretende ser una revisión exhaustiva de la obra del autor, se centrará en los temas: mundo histórico, vivencia y método comprensivo de investigación. Para finalizar, se realizará un ejercicio imaginativo de cómo sería la psicología actualmente si la posición de Dilthey se hubiera vuelto hegemónica en el campo.

Palabras clave: Dilthey; Ciencias del Espíritu; Psicología; Fenomenología; Método.

\section{Introdução}

Esse artigo se propõe a discutir um autor ainda pouco explorado no Brasil pelas ciências psicológicas: Wilhelm Dilthey (1833-1911). O filósofo alemão, defensor das ciências do espírito ${ }^{1}$ (Geisteswissenschaften), foi um dos primeiros autores a assinalar a clara diferença entre o método das ciências naturais e das ciências humanas (e também a possibilidade de articular esses dois métodos dependendo do objeto estudado), desenlaçando assim a psicologia das amarras que buscavam causalidade para os fenômenos humanos e focando na vivência enquanto objeto de estudo, promoveu o desenvolvimento de uma ciência qualitativa rigorosa e válida.

Ao analisar o trabalho de Dilthey, Franco (2012) afirma que é preciso reconhecer as influências cruzadas entre as ciências humanas, ou ciências do espírito como Dilthey se referia, e as ciências naturais

1 Para Dilthey (1970/2010), espírito diz respeito à cultura, à moral e às produções humanas. Esse termo era de uso recorrente na época e não tem relação com o uso feito dentro das comunidades religiosas.
(Naturwissenschaft), existindo continuidades e descontinuidades entre as duas. Para fortalecer a posição de Dilthey, não convém nem separá-las demais, afinal ambas são ciências, e nem aproximá-las demais, já que seus objetos são diversos.

A maneira que Dilthey encontra para realizar a tarefa de fundamentar as ciências do espírito é delineando o seu objeto e validando os métodos qualitativos - validade essa que ainda é muito discutida no mundo acadêmico. Com a delimitação das ciências do espírito se torna possível tanto articulá-las com as ciências naturais, como também desmembrá-las em áreas de saber específicas: história, filosofia, psicologia, sociologia, ciência política e antropologia, para citar algumas dessas matérias que hoje são alocadas nos departamentos de ciências humanas ou sociais.

Todavia, o surgimento das ciências humanas é bastante paradoxal, pois ao mesmo tempo em que reivindicam um estatuto próprio, por vezes os campos nascentes ficaram a sombra das ciências natu- 
rais, dos seus métodos e da sua epistemologia (Vandenberghe, 2010; Amaral \& Muhl, 2017; Lessing, 2019; Sass, 2019). Assim, é como se houvessem dois movimentos ${ }^{2}$ distintos de formação da psicologia: aquele que estava sendo feito nos laboratórios, através de experimentos e buscando elaborar leis gerais e um outro que entendia que a vivência humana não era passível de quantificação e se dedicava a elaborar métodos próprios para o campo psicológico.

Como representantes do campo experimental foram citados nominalmente por Dilthey (1894/2008): Johann Herbart, Hebert Spencer, James Mill, John Stuart Mill, Hippolyte Taine e Wilhelm Wundt, entre outros. Já a proposta de uma psicologia enquanto ciência do espírito foi disparada por Dilthey. Ao olhar retrospectivamente, vemos que a obra diltheyana influenciou muitos autores dessas ciências humanas que nasciam, porém, não era o pensamento hegemônico no campo, assim, até hoje os pesquisadores em psicologia que usam métodos qualitativos precisam afirmar e reafirmar a validade das suas pesquisas, que recebem críticas de não serem cientificas o suficiente.

Tendo isso posto, o objetivo desse texto é pensar quais foram as contribuições de Dilthey para a Psicologia, em especial aquela inspirada na fenomenologia, dada a proximidade do pensamento diltheyano com aquele desenvolvido por Husserl. Indo mais além, pretende-se também pensar como seria a psicologia atualmente se o pensamento de Dilthey tivesse prosperado entre os psicólogos da época, como um exercício imaginativo.

A análise será centrada na obra Ideias Sobre Uma Psicologia Descritiva e Analítica (Ideen über eine beschreibende und zergliedernde Psychologie), datada originalmente de 1894. Outras obras do autor serão acessadas no decorrer do texto para ilustrar os argumentos, mas o texto não se propõe a ser uma revisão exaustiva da produção de Dilthey.

\section{Projeto de Dilthey}

Wilhelm Dilthey nasceu em 1833 na Alemanha, estudou nas Universidades de Heidelberg e Berlim, e apesar de seu grande interesse por História, ele acaba se formando em Teologia por pressão de seu pai. Torna-se professor secundário e, posteriormente, professor universitário e pesquisador nas áreas de História e Filosofia, tendo ministrado aulas nas Universidades de Berlim e da Basiléia. A maior parte da obra de Dilthey só foi publicada após a sua morte em 1911 (Franco, 2012).

Uma das preocupações centrais nas obras de Dilthey (1894/2008, 1970/2010) é a delimitação das ciências do espírito, que para o autor seriam todas as ciências que "descrevem, narram, julgam e formam conceitos e teorias em relação ao mesmo grande fato: 2 Vandenberghe (2010) retrata esse mesmo evento na sociologia, ao que ele chama de "dupla fundação". Na sociologia os embates fundadores seriam entre a física social de Auguste Comte e a ciência do espirito de Wilhelm Dilthey ou entre a Sociologia funcionalista de Emile Durkheim e a Sociologia Compreensiva de Max Weber. a espécie humana" (Dilthey, 1970/2010, p. 20). A particularidade destas em relação às ciências naturais - a grande contraposição da sua época - são que as ciências do espírito não trabalham a partir da cisão entre o físico e o psíquico: o cientista do espírito estuda a conexão viva entre os dois. Assim, o humano é abordado em toda sua complexidade, como natureza (enquanto corpo biológico e impulsos), como consciência (em suas diversas manifestações, sejam elas pensamento, comunicação, entre outras) e também como cultura e história (nas instituições criadas pelos seres humanos, como Estado, igreja, escola).

Um exemplo da diferença de objeto entre as ciências naturais e as ciências do espirito é trazida por Sá (2009, p.40):

Enquanto o método científico-natural baseia-se na "explicação" pelo esclarecimento das conexões causais, as ciências do espírito se fundam na "compreensão" enquanto apreensão de sentido. Assim como se pode explicar, por exemplo, o rubor de uma face pela vasodilatação produzida por alterações hormonais, pode-se também compreendê-la enquanto expressão de pudor ou de raiva no contexto de uma situação de vida. No primeiro caso constrói-se "representações" abstratas dos fenômenos observados, no segundo tem-se deles a "vivência" (Erlebnis) ou "experiência" (Erfahrung).

Alguns comentadores, entre eles Reis (2003), assinalam que o pensamento diltheyano localizaria uma descontinuidade insuperável entre as ciências do espírito e as ciências naturais, sendo que a primeira diferença geral entre as duas é a diferença de objeto - acima apresentada - e a segunda diferença geral é em relação ao método. As ciências do espírito se fomentam, e consolidam seu objeto, na medida em que estados humanos são vivenciados, ganham significado e expressão e essas expressões são compreendidas. É justamente nessa conexão entre vivência, expressão e compreensão que Dilthey (1970/2010) localiza o método para as ciências do espírito.

Dilthey (1970/2010) compreende métodos diferentes como caminhos diferentes para resolver um problema, não havendo, portanto, radicalidade no seu posicionamento metodológico. Como o objeto das ciências do espírito tem um caráter particular, os seus problemas são distintos e precisam de um caminho diferente daquele que era predominante na ciência da época:

Um método científico surge na medida em que formas de pensamento e capacidades gerais do pensamento são ligadas para formar uma totalidade composta pela finalidade estabelecida na solução de uma determinada tarefa científica. Se há problemas similares a essa tarefa, então o 
método aplicado a uma região limitada se comprova como frutífero em uma região mais abrangente (Dilthey, 1970/2010, p. 83, grifo do autor).

É a possibilidade de ampliar um método para problemas semelhantes que embasa a contribuição de Dilthey para a Psicologia e, também, para a Sociologia, a História, a Filosofia, a Arte e a Literatura, mas essa tarefa só estará completa no momento em que o método for entendido como uma maneira de fazer avançar o conhecimento, afastando-se de fidelidades ideológicas ou totalizantes. Nessa perspectiva "toda ciência é circunstancial e pode utilizar qualquer caminho para se desenvolver - o das ciências naturais ou das ciências humanas - conforme a necessidade inerente à pesquisa” (Amaral \& Muhl, 2017, p. 44).

\section{0 que há de Dilthey na fenomenologia e na psicologia?}

Primeiramente precisamos explicitar quais os projetos de psicologia e de fenomenologia que estamos acionando neste trabalho, uma vez que há disputas teóricas e metodológicas nesse campo. Mobilizamos aqui a psicologia enquanto uma ciência do espírito, aquela que se afasta da influência do positivismo, do naturalismo e do objetivismo. E por fenomenologia estamos fazendo referência as concepções de Husserl, que se dedica a compreensão dos fenômenos que estão intencionalmente presentes a consciência e tem para esta um significado (Zilles, 1996).

O diálogo entre Husserl e Dilthey se dá tanto pelo fato deles compartilharem o mesmo contexto histórico ${ }^{3}$ - Alemanha na passagem para o século $\mathrm{XX}$ - como pela proximidade do projeto dos dois autores, já que tanto para Husserl como para Dilthey a psicologia tem um papel central no desenvolvimento de suas obras. Psicologia essa em que se pode visualizar um contínuo começando com a proposição de método descritivo e analítico de Dilthey (1894/2008) até chegar à proposta de que o substrato epistemológico da psicologia deve ser a fenomenologia em Husserl (1910/1965). Todavia, no decorrer da produção dos autores, a psicologia vai perdendo espaço, até quase desaparecer, onde Dilthey passa a se concentrar na história e Husserl desenvolve trabalhos cada vez mais filosóficos.

Num primeiro momento uma aproximação entre Husserl e Dilthey pode parecer estranha, já que, por exemplo, na obra A Filosofia como Ciência de Ri-

\footnotetext{
3 Edmund Husserl (1859-1938) comanda um dos principais círculos de produção filosófica da época na Alemanha. Sua formação foi realizada nas cidades de Leipzig, Berlim e Viena, nas áreas de filosofia e matemática. Depois de defender sua tese de doutorado, deu aulas na Universidade de Halle, Universidade de Göttingen e Universidade de Freiburg. Sendo afastado do ambiente acadêmico pela legislação antissemita da época, continuou trabalhando e fazendo conferencias fora do país. Sua obra continua tanto com o trabalho dos seus discípulos, como nos seus manuscritos (Husserliana) que ainda estão sendo traduzidos e estudados (Zahavi, 2015). A biografia e o contexto de trabalho de Dilthey já foi apresentado anteriormente.
}

gor de 1910 Husserl (1910/1965) dedica um capítulo inteiro a crítica do Historicismo, escola defendida por Dilthey, chegando inclusive a fazer críticas diretas a este, como podemos observar na seguinte nota de rodapé da referida obra:

Dilthey refuta igualmente o cepticismo historicista; mas eu não compreendo como ele pode julgar que a sua análise, tão instrutiva da estrutura e do tipismo das ideologias, lhe haja proporcionado razões decisivas contra o cepticismo. Pois, como está exposto no texto, uma ciência moral, mas empírica, não pode argumentar nem contra, nem a favor de algo que pretenda ter valor objectivo. $\mathrm{O}$ caso modifica-se - e parece ser isto que ultimamente preocupa o seu pensar - quando a orientação empírica que mira à compreensão empírica, e é substituída pela orientação fenomenológica que mira o Ser (Husserl, 1910/1965, p.53).

A crítica ao pensamento de Dilthey se dá pelo entendimento de Husserl (1910/1965) de que o Historicismo era relativista e perspectivista, e que não há validade em um pensamento subjetivista como este. Cabe lembrar que o projeto de Husserl sempre foi de elaborar uma ciência de rigor, que eliminasse o subjetivismo, porque só assim uma ciência teria validade. Entretanto, é possível ver a presença de Dilthey no pensamento de Husserl ${ }^{4}$, comentadores consultados para desenvolver esse estudo como Farber (2012), Franco (2012) e Holanda (2014) defendem a presença dessa influência, e o próprio Dilthey, em correspondências trocadas com Husserl (1973), fala sobre os pontos de convergência do pensamento de ambos, como a preocupação com a validade das ciências do espírito e a importância do pensamento filosófico.

Na última fase do pensamento husserliano, a partir de 1930, surge a preocupação com a história, que já era um tópico nos estudos de Dilhtey, e Husserl chega mesmo a afirmar que "Eu vejo a ingenuidade no fato de o cientista não levar em conta em sua tarefa a historicidade como algo que essencialmente a acompanha” (1934/2007, p. 664). Na obra A crise da Humanidade Europeia e a Filosofia essa preocupação continua e Husserl (1935/1996) reconhece a centralidade da história, da psicologia e de uma metodologia adequada para a constituição das ciências do espírito, se reconciliando com o pensamento diltheyano.

Mas em nosso tempo anuncia-se, em toda a parte, a premente necessidade de uma compreensão do espírito e se tornou quase insuportá-

$4 \quad$ Neste trabalho nos ocupamos apenas da influência de Dilthey na obra de Husserl, mas ressaltamos que essas influências foram cruzadas e que Dilthey realizou extensivos estudos sobre as obras de Husserl, em especial Investigações Lógicas e chegou até mesmo a proferir uma série de seminários sobre ela (Peres, 2014). 
vel a confusão que afeta as relações de método e de conteúdo entre as ciências da natureza e as ciências do espírito. Dilthey, um dos maiores cientistas do espírito, dedicou toda a energia de sua vida ao esclarecimento das relações entre a natureza e o espírito, ao esclarecimento da contribuição da psicologia de tipo psico-física, a qual, como ele acreditava, deveria ser completada por uma psicologia nova, descritiva e analítica (Husserl, 1935/1996, p. 62).

Nesta obra, Husserl trabalha com a noção de "mundo circundante" (Lebensumwelt) que entende o humano - e a subjetividade humana - como sendo históricas e relacionais, o que recupera argumentos do pensamento de Dilthey. O mundo circundante é um domínio que se estende no espaço e no tempo ao redor do humano e no qual ele mesmo se inclui, bem como "suas tradições, seus deuses, seus demônios, suas potências míticas” (Husserl, 1935/1996, p. 52).

Como características do mundo circundante podemos citar que ele é uma formação espiritual e histórica, ou seja, cultural:

Mundo circundante é um conceito que tem seu lugar exclusivamente na esfera espiritual. Que nós vivemos em nosso respectivo mundo circundante, ao qual estão dirigidas todas as nossas preocupações e esforços, designa um fato que sucede puramente no plano espiritual. Nosso circum-mundo é uma formação espiritual em nós e em nossa vida histórica. (Husserl,1935/1996, p. 46).

As proposições husserlianas levam a compreensão de que não experenciamos o mundo todo ao mesmo tempo, pelo contrário, somos envolvidos por uma parcela do mundo, o mundo da vida cotidiana e que está ao alcance, que é datado historicamente e é o local onde nascemos, aprendemos, agimos. Ainda que migrarmos em algum momento da vida, encontrando um novo mundo circundante, essas primeiras vivências já estarão marcadas no nosso ser $^{5}$. Nenhum humano escapa do mundo, da cultura ou da história.

Isso posto, podemos observar a análise que Husserl faz do seu próprio mundo circundante, a Europa:

Colocamos a seguinte questão: o que caracteriza a estrutura espiritual da Europa? [...] Trata-se aqui de uma unidade de vida, de uma ação, de uma criação de ordem espiritual, incluindo todos os objetivos, os interesses, as preocupações e os esforços, as obras feitas com uma intenção,

$5 \quad$ Schutz aborda essa questão no texto $O$ estrangeiro (2010) em que demonstra que um migrante não se encaixa completamente em um novo lugar de vida porque não tem as experiências prévias que os locais possuem, assim, mesmo que ele faça um esforço para viver de acordo com os códigos de seu novo mundo circundante, ele será visto como um estrangeiro. as instituições e as organizações. Nelas atuam os indivíduos dentro de sociedades múltiplas de diferentes graus de complexidade, em famílias, raças, nações, nas quais todos parecem estar interior e espiritualmente vinculados uns aos outros e, como disse, na unidade de uma estrutura espiritual (Husserl, 1935/1996, p. 47).

O mundo circundante, o mundo em que a vida acontece, tem como característica essencial o fato de não ser estático, tendo uma história de surgimento e um constante desenvolvimento (Zahavi, 2015). Esse fator permite que Husserl fale da unidade da Europa, apesar das suas transformações ao longo do tempo. Outro elemento importante é a sua concreticidade, já que ele está a nossa volta, nos envolvendo e limitando, como remarca Dilthey:

Entre estas experiências da vida, as que se baseiam na realidade do mundo exterior e nas minhas relações com ele são as mais importantes, pois restringem a minha existência, exercem sobre ela uma pressão que não posso pôr de lado e impedem de forma inesperada e insuperável as minhas intenções. O complexo das minhas induções, a soma do meu saber funda-se nestes pressupostos baseados na consciência empírica (Dilthey, 1977/1992, p.12).

A preocupação com o mundo onde a vida acontece e com o empírico aparece para Husserl diante da sua concepção de humano encarnado, onde todo o espírito humano estaria atado à sua corporeidade: "tudo que é dado no espaço e no tempo, tem, pelo menos em sua base, a forma existencial da corporeidade” (Husserl, 1935/1996, p. 58). Por conseguinte, essa corporeidade é compartilhada com os outros, com a comunidade e com o mundo circundante.

Mas como estudar esse humano na história e no mundo da vida, que se apresenta como o "novo" objeto das ciências do espirito? Uma filosofia forte e bem postada é a resposta tanto de Dilthey como de Husserl. Eles também convergem no caminho para se chegar a essa filosofia forte: o questionamento da filosofia corrente à época - virada do século XIX para o século XX (Dilthey, 1984/2014; Zahavi, 2015). Nesta época em que as ciências naturais (e seus métodos) dominavam as produções científicas, Husserl (1986, 1910/1965) propunha uma orientação nova para a filosofia, estabelecendo fins e métodos especificamente filosóficos para a resolução dos problemas, desenvolvimento de teorias e esclarecimento de significados, pois na sua avaliação, a filosofia ainda não havia alcançado a pretensão de ser uma ciência de rigor.

Aos olhos de Dilthey, a filosofia não pode se contentar em fornecer apenas uma especulação sobre o mundo. O seu objetivo enquanto ciência deve ser o de proporcionar conhecimentos teóricos e, a 
partir desses conhecimentos teóricos, princípios práticos reguladores para a vida, tanto para os seres individuais como para a sociedade como um todo (Amaral, 2004). A vida ${ }^{6}$ (Leben) aqui citada é tema central para os dois autores (Holanda, 2014). Husserl (1935/1996) identifica na vida dos seres humanos, em suas realizações e suas experiências, o interesse central das ciências do espírito. Vida que ultrapassa o entendimento das ciências naturais: "A palavra vida aqui não tem sentido fisiológico, é uma vida cuja atividade possui fins que cria formas espirituais: vida criadora de cultura, em sentido mais amplo, numa unidade histórica” (Husserl, 1935/1996, p 44).

Assim, considerando o aspecto histórico, a noção genérica de vida é aprimorada e ganha na obra de Dilthey uma unidade constituidora que é a vivência. Essa unidade também está presente na fenomenologia como experiência vivida. Vejamos então o posicionamento de Husserl (1929/1992, p. 34) sobre o ato de experienciar:

Experimento em mim mesmo, no âmbito da minha vida [...], tudo e cada um, e experimento o mundo não como simplesmente o meu mundo privado, mas como um mundo intersubjetivo, dado a cada um e acessível nos seus objetos, e nele experimento os outros enquanto outros e, ao mesmo tempo, enquanto uns para os outros, para cada um.

Definir o que é experiência pode ser uma tarefa paradoxal, uma vez que é difícil mostrar qual é sua especificidade já que experienciamos o mundo e as coisas do mundo - o tempo todo. Isso posto, partimos do entendimento que "todo o objeto existente é objeto de um universo de experiências" (Husserl, 1929/1992, p. 24), sendo então o ato de experienciar uma constante na vida de qualquer pessoa.

Avançando nessa discussão, Dilthey (1894/2008) compreende que é na experiência vivida que podemos encontrar a expressão da individualidade de uma pessoa, o que a faz singular. Assim:

[...] experiência é a forma original pela qual os sujeitos concretos vivenciam o seu mundo. Em outras palavras, experiência diz respeito ao modo de ser do sujeito no mundo. É o meio pelo qual o mundo se coloca face a nós e dentro de nós e, como tal, está sempre localizada no tempo e no espaço (Alves, 2006, p. 1551).

Na obra de Dilthey (1970/2010), é no elemento vivencial que está contido todo o valor da vida: é ele que traz significação, valoração e finalidade para as

$6 \quad$ Lessing (2019) e Sass (2019) destacam a centralidade do conceito na obra de Dilthey. Segundo Sass, existe uma conexão indissociável entre ciências do espírito e vida, “[...] em particular a vida humana historicamente construída. É esse o fato e o dado fundamental a partir do qual as ciências do espírito são elaboradas” (2019, p. 539). Sendo a vida, "não é uma potência metafísica, mas o primeiro e último fato do filosofar mesmo" (Lessing, 2019, p.18). ações. Amaral (2004) complementa que a vivência é a própria vida reduzida nas suas proporções mais significativas, sendo a zona limite do conhecimento e, também, o fundamento de todo conhecer, ressaltando as preocupações epistemológicas de Dilthey. Vejamos:

Da reflexão sobre a vida nasce a experiência da vida. Os acontecimentos singulares que o feixe de impulsos e sentimentos em nós suscita na sua confluência com o mundo circundante e com o destino convertem-se nela num saber objectal e universal (Dilthey, 1977/1992, p. 10).

A fenomenalidade da vivência é fértil de conteúdos e a compreensão destes conteúdos é a base para a construção de um novo projeto de ciência (e de Psicologia) que se dedique à compreensão do humano no mundo. Com esse movimento, a ciência não mais ficaria presa aos conceitos teóricos e abstratos e passaria efetivamente a considerar a história, o mundo, a corporeidade, a consciência no seu fazer (Muhl \& Holanda, 2016). Isso posto, Lessing (2019, p. 23) sintetiza que "A vivência e a compreensão constroem a base das ciências humanas".

Questionando qual é o estatuto de ciência que queremos e remarcando esse novo objeto de investigação - a vida - Husserl entende que só existe um caminho possível: a fenomenologia.

[...] o maior passo a dar pela nossa época, reconhecer-se que a intuição filosófica no sentido autêntico, a percepção fenomenológica do Ser, abre um campo imenso de trabalho e leva a uma ciência que, sem todos os métodos indiretamente simbolizantes e matematizantes, sem o aparelho das conclusões e provas, não deixa de chegar a amplas intelecções das mais rigorosas e decisivas para toda a Filosofia ulterior (Husserl, 1910/1965, p. 73, grifos do autor).

Esse questionamento da filosofia e a proposição de um novo tipo de ciência une Dilthey e Husserl. Não pretendo, contudo, afirmar que Dilthey fosse um fenomenólogo, tão somente que ao incitar o projeto de uma ciência humana autônoma, ele abre as portas para a possibilidade da fenomenologia. Esse projeto é encontrado principalmente na obra de 1984, Ideias para uma psicologia descritiva e analítica, onde Dilthey (1894/2008) propõe uma ciência nova e original, baseada na compreensão, no lugar da até então corrente psicologia explicativa, que analisava os fenômenos psíquicos através de uma perspectiva causalista e baseava-se nos métodos das ciências naturais.

Essa proposta inovadora de Dilthey traz com ela uma importante requisição: a autonomia do método das ciências do espírito. 
[...] queremos proclamar a pretensão das ciências do espírito de determinar autonomamente os seus métodos, de harmonia com o seu objeto. As ciências do espírito, partindo dos conceitos mais gerais da metodologia geral, devem chegar, graças à comprovação nos seus objetos peculiares, a métodos e a princípios mais genuínos dentro do seu âmbito, tal como fizeram as ciências da natureza (Dilthey, 1894/2008, p.15).

Zahavi (2015) também identifica na obra de Husserl a crítica à ciência natural e a proposição de um novo modelo de fazer científico. A critica vai no sentido de que ao se proporem objetivas e dogmáticas, as ciências naturais desenvolvem suas pesquisas a partir de pressupostos, suposições, convicções e verdades vigentes, sem que haja uma reflexão sobre as questões epistemológicas envolvidas na pesquisa. A saída que Husserl oferece é uma ciência que se preocupe em como o humano conhece, isso leva necessariamente a um questionamento dos pressupostos do cientista ${ }^{7}$ e um voltar-se ao mundo e às coisas mesmas (Husserl, 1986; 1934/2007).

Retomando o mote do método: uma questão importante que diferencia as ciências naturais das ciências do espírito é o objeto, já que enquanto as primeiras se detêm em fatos e aspectos vindos de fora da consciência, as ciências do espírito têm como seu objeto a vivência, qual seja, algo que se apresenta vindo de dentro, como uma realidade ou uma conexão vivida (Dilthey, 1894/2008). Devemos então nos questionar que método poderia dar conta desse objeto tão peculiar que é a experiência vivida ou a vida espiritual? Na resposta dessa pergunta temos a grande contribuição de Dilthey para a psicologia: a elaboração de um método compreensivo. Em seu projeto epistemológico,

Dilthey pretende fundar uma psicologia descritiva e analítica, que abordaria a vida psíquica sem submetê-la a um conjunto de hipóteses, sem separar gnosiologia e psicologia, como fez a psicologia explicativa, que não foi capaz de elevar suas hipóteses ao nível de teorias científicas. Esta imitação do método das ciências naturais pela psicologia explicativa, longe de trazer segurança e rigor ao conhecimento, trouxe descontrole dos resultados de pesquisa (Reis, 2003, p. 107).

Para enrijecer a psicologia, Dilthey parte da seguinte proposição “'Explicamos' a natureza e 'compreendemos' a vida anímica” (Dilthey, 1894/2008, p.15) e assim desenvolve um método capaz de produzir conhecimento sobre a experiência vivida das

$7 \quad$ Essa postura pode ser entendida como a Redução fenomenológica, importante conceito da fenomenologia, que aqui apresentamos segundo o entendimento de Ales Bello (2014), e versa sobre o modo como na prática da ciência é preciso reduzir toda aceitação acrítica, colocar entre parênteses toda atitude preestabelecida, para então assumir um posicionamento epistemológico vigilante. pessoas. Método que, no entendimento do autor, deveria ter como características ser descritivo e analítico, como forma de escapar das relações causais e do esquema de formular hipóteses para depois comprová-las. A vida supera qualquer hipótese pré-definida.

Segundo Franco (2012), quando Dilthey propõe um método compreensivo ele está falando basicamente da busca de um conhecimento que possa ser testado, descrito e psicologicamente sustentado. A compreensão, portanto, não se aproxima de uma apreensão especulativa ou mesmo do conceito de empatia, ela se apresenta como uma mediação ou um caminho que ao investigar as ações humanas, debruça-se sobre o conteúdo e o significado "vivenciado, compreendido e descrito" dessas ações (Dilthey, 1984/2014).

A compreensão se dedica a reconhecer o que acontece no espírito, os significados da vida psíquica e como o humano pode conhecer algo, e é neste último ponto que a psicologia se coloca como um imperativo no pensamento de Dilthey. Mesmo considerando as ciências do espírito um agregado de saberes, os conhecimentos psicológicos têm um papel central ${ }^{8}$, pois são eles que permitem entender a trama psíquica que se revela em cada ação humana. Destarte, “[...] nenhuma tentativa de estabelecer uma ciência empírica do espírito sem psicologia pode levar a um resultado útil” (Dilthey, 1894/2008, p.19).

Resumindo o que foi exposto até agora, podemos dizer que Dilthey provoca três viragens na ciência. Acompanhemos o pensamento de Cohn:

Seu pensamento articula-se em torno de três grandes oposições: entre o mundo histórico criado pelo homem e a natureza não criada por ele; entre a explicação dos fenômenos a partir do exterior, no caso da natureza, e a compreensão interna de obras humanas, no caso da história; e entre o estudo de segmentos isolados e atomizados do real, no caso da natureza, e a apreensão integradora de formas de vivência nas ciências do espírito (Cohn, 2003, p. 22; grifos do autor).

Essas viragens só podem acontecer partindo do entendimento da vida enquanto fluxo (Cohn, 2003). Desse modo, a história precisa ser considerada já que as pessoas nascem em um mundo que existe antes delas, as vivências precisam ser compreendidas, já que não existe nexo causal que as explique, e a unidade da vida anímica deve ser observada, já que partes isoladas dos processos psicológicos e das ações humanas não formam vida.

8 No Brasil, há o costume de definir a psicologia em dois aspectos: ciência e profissão. Quando Dilthey fala da importância da psicologia claramente ele está falando dos seus achados científicos e da sua capacidade de compreender os processos psicológicos da vida anímica. Com essas contribuições, Dilthey (1894/2008, p. 31) afirma que "a psicologia transformar-se-á no instrumento do historiador, do economista, do político e do teólogo; poderá assim dirigir e guiar também o observador dos homens e o homem prático". 


\section{Considerações Finais}

Uma ciência nunca é uma idealidade ou imparcial, ela é sempre fruto da sua época, reflexo do seu contexto histórico. Dilthey está desenvolvendo seu projeto de psicologia descritiva na mesma época que os psicólogos experimentais estavam dentro dos laboratórios fazendo seus testes e medições, o que nos leva a questionar: o que teria acontecido com a psicologia se o projeto de Dilthey tivesse prevalecido?

Talvez o impacto mais direto que observaríamos seria na metodologia de pesquisa, onde mais de 100 anos depois das publicações de Dilthey, ainda precisamos lutar para que a pesquisa qualitativa seja vista como um conhecimento válido. Até hoje a postura metodológica qualitativa sofre acusações de que seria relativista, portanto, uma ciência fraca, que não cumpriria às exigências de uma ciência rigorosa, precisa, quantificável. Apesar de ter anos de resultados acumulados e ter trazido reflexões importantes para a ciência, todo pesquisador que usa metodologia qualitativa começa sempre o seu método se justificando por sua escolha, tentando sair da sombra das ciências naturais.

Outro efeito importante seria perceber como a história importa para a vida das pessoas, assim, ela também tem reverberações nos processos psicológicos e nas ações humanas. As formas de ser e agir no mundo mudam de época para época, não temos os mesmos costumes que existiam na sociedade de Dilthey, desse modo, é preciso rever constantemente os padrões culturais em que as pessoas estão envolvidas e rever também a forma de atuar em psicologia no contexto em que se está inserido. Há muita psicologia ainda sendo feita atualmente no Brasil como nas primeiras décadas do século XX na Europa, seguindo os cânones dessa ciência à risca.

Destarte, ainda não é tarde demais para recuperar Dilthey. Para pensar como a vida pulsa e acontece sempre em fluxo. Para não nos fecharmos numa ciência hermética, que estuda o mundo, mas não se deixa afetar por ele.

\section{Referências}

Ales Bello, A. (2014). Edith Stein: A paixão pela verdade. Curitiba: Juruá.

Alves, P. C. (2006). A fenomenologia e as abordagens sistêmicas nos estudos sócio-antropológicos da doença: breve revisão crítica. Cadernos de Saúde Pública, 22(8), 1547-1554.

Amaral, M. N. P. C. (2004). Dilthey - conceito de vivência e os limites da compreensão nas ciências do espírito. Trans/Form/Ação, 27, 51 - 73.

Amaral, F. B. \& Muhl, C. (2016). Fundamentos em ciências sociais. Curitiba: Intersaberes.

Cohn, G. (2003). Crítica e Resignação: Max Weber e a teoria social. São Paulo: Martins fontes.
Dilthey, W. (1992). Os tipos de concepção de mundo. Corvilhã: Lusosofia. (Original publicado em 1977).

Dilthey, W. (2008). Ideias acerca de uma Psicologia Descritiva e Analítica. Corvilhã: Lusosofia. (Original publicado em 1894).

Dilthey, W. (2010). A construção do mundo histórico nas ciências humanas. São Paulo: Unesp. (Original publicado em 1970).

Dilthey, W. \& Husserl, E. (1973). Correspondência entre Dilthey y Husserl. In: Husserl, E. La filosofia como ciencia estricta (pp 75-87). Buenos Aires: Nova.

Farber, M. (2012). Edmund Husserl e os fundamentos de sua Filosofia. Revista da Abordagem Gestáltica, XVIII (2), 235-245. (Original publicado em 1940).

Franco, S. G. (2012). "Dilthey: compreensão e explicação" e possíveis implicações para o método clínico. Rev. Latinoam. Psicopat. Fund., 15, 1426.

Holanda, A.F. (2014). Fenomenologia e Humanismo: Reflexões Necessárias. Curitiba: Juruá.

Husserl, E. (1965). A Filosofia como ciência de rigor. Coimbra: Atlântida. (Original publicado em 1910).

Husserl, E. (1986). A Ideia da Fenomenologia. Lisboa: Ed.70.

Husserl, E. (1992). Conferências de Paris. Corvilhã: Lusosofia. (Original publicado em 1929).

Husserl, E. (2007). A ingenuidade da ciência. ingenuidade da ciência. Scientiæ Zudia, São Paulo, v. 7, n. 4, p. 659-67. (Original publicado em 1934).

Husserl, E. (1996). A crise da humanidade europeia e a filosofia. Porto Alegre: EDIPUCRS. (Original publicado em 1935).

Lessing, H. U. (2019). Wilhelm Dilthey - O filósofo das ciências humanas. Aoristo. Toledo, v. 1, n. 3, p. 14-30.

Muhl, C., \& Holanda, A. F. (2016). "Duas faces da mesma moeda": vivência dos psicólogos que atuam na rede de atenção psicossocial. Revista da Abordagem Gestáltica, 22(1), 59-67. Recuperado em 30 de outubro de 2018, de http://pepsic.bvsalud.org/scielo.php?script=sci_arttext\&pi$\mathrm{d}=$ S1809-68672016000100008\&lng $=$ pt\&tlng $=$ pt.

Peres, S. P. (2014). Husserl e o projeto de Psicologia descritiva e analítica em Dilthey. Memorandum, 27, 12-28. 
Reis, J. C. (2003). Wilhelm Dilthey e a autonomia das ciências histórico-sociais. Londina: Eduel.

Sá, R. N. (2009). As contribuições de Dilthey para uma fundamentação hermenêutica das Ciências Humanas. Boletim Interfaces da Psicologia da UFRuralRJ. (1), 38-43.

Sass, S. (2019). O método compreensivo na obra de Dilthey. Revista de Filosofia Aurora, 31(53). doi:http://dx.doi.org/10.7213/19805934.31.053.DS09

Schutz, A. (2010). O Estrangeiro: Um ensaio em Psicologia Social. Espaço Acadêmico, Maringá, v. 10, n. 113, p.117-129,

Vandenberghe, F. (2010). "O real é relacional": uma análise epistemológica do estruturalismo gerativo de Pierre Bourdieu. Tradução de Gabriel Peters. Disponível em: http://frederic.vdb. brainwaves.be/Frederic_Vandenberghes_Personal_Website/Texts to_Download_files/Orealerelacional-vandenberghe.pdf

Zahavi, D. (2015). A fenomenologia de Husserl. Rio de Janeiro: Via Verita.

Zilles, U. (1996). A Fenomenologia husserliana como método radical. In: Edmund Husserl, E. A crise da humanidade europeia e a filosofia. Porto Alegre: EDIPUCRS.

Camila Muhl (orcid.org/0000-0003-4054-6035) é Doutora em Sociologia pela Universidade Federal do Paraná. Mestra em Psicologia pela Universidade Federal do Paraná. Especialista em Sociologia Política pela Universidade Federal do Paraná. Psicóloga pela Universidade do Oeste de Santa Catarina. Professora do curso de Psicologia da FAE Centro Universitário. Email: came.muhl@gmail.com

Recebido em 19.11.2018

Primeira Decisão Editorial em 17.10.2019

Aceito em 31.01.2020 